\title{
Retrospective analysis of ovarian torsion incidence in 5186 women undergoing controlled ovarian hyperstimulation
}

\author{
๑DNur Dokuzeylül Güngör1 ${ }^{1}$, Arzu Yurci², @Mehmet Güçlü̈ \\ ${ }^{1}$ Medical Park Göztepe Hospital, Department of Obstetrics and Gynecology, İstanbul, Turkey \\ ${ }^{2}$ Memorial Hospital IVF Center, Department of Obstetrics and Gynecology, Kayseri, Turkey \\ ${ }^{3}$ Marmara University, Pendik Education and Research Hospital, Department of Obstetrics and Gynecology, İstanbul, Turkey
}

Cite this article as: Dokuzeylül Güngör N, Yurci A, Güçlü M. Retrospective analysis of ovarian torsion incidence in 5186 women undergoing controlled ovarian hyperstimulation. J Health Sci Med 2021; 4(5): 630-633.

\begin{abstract}
Aim: Ovarian torsion (OT) is one of the common gynecologic emergencies in reproductive age women. In our study, it is aimed to make a retrospective evaluation of OT cases developed after controlled ovarian stimulation (COH) for in vitro fertilization (IVF) treatment.

Material and Method: This retrospective study was carried out in an IVF clinic between January 2015- December 2020 . Ten cases who definitely diagnosed as OT were included in this study. The medical records of these patients were examined. Data were analyzed according to demographic, clinicopathological, and sonographic findings.

Results: Ten of 5186 IVF patients developed OT $(10 / 5186 ; 0.19 \%)$ and all OT cases were PCOS. The mean age of OT patients was $27.3 \pm 4$.1years and the mean body mass index (BMI) was $23.5 \pm 6.2 \mathrm{~kg} / \mathrm{m}^{2}$ respectively. The mean number of retrieved oocytes was $21.46 \pm 4.12$. The average diameter of the twisted ovaries of patients was $121.4 \pm 56.1 \mathrm{~mm}$. Laparoscopy was performed in all OT patients for detorsion of the ovaries. It was found that OT occurred more frequently on the right side (8/10; 80\%).

Conclusion: OT is more common in cases with polycystic ovary syndrome (PCOS). The risk of OT is reduced by decreasing gonadotropin dosage as well as retrieved number of oocyte. Also, prefering frozen-thawed embryo transfer can decrease OT risk in PCOS patients.
\end{abstract}

Keywords: Ovarian torsion, in vitro fertilization, polycystic ovary syndrome

\section{INTRODUCTION}

In vitro fertilization (IVF) is a sequence of steps which starts with controlled ovarian hyperstimulation $(\mathrm{COH})$ which is provided by exogenous gonadotropins (1). Polycystic ovary syndrome (PCOS) is the most common endocrine disorder of reproductive-aged women and IVF is also performed in PCOS patients resistant to all other alternative treatments. The aim of $\mathrm{COH}$ is to obtain as many good quality oocytes as possible (2). The ideal stimulation regimen for IVF should have minimal side effects, the lowest cycle cancellation rates, the least drug cost, easy monitoring, and single pregnancy should be achieved ultimately (3). Ovarian reserve should be clearly evaluated in every woman in whom IVF is planned. The number of antral follicles and Anti-müllerian hormone (AMH) levels are two important factors for determination of gonadotropine regimen. Applying the same protocol for each case limits the success of the treatment. The development of acute abdominal pelvic pain shortly after assisted fertility treatment is often attributed to hyperstimulation of the ovaries. Ovarian torsion (OT) is one of the most common gynecologic emergencies in reproductive age women. The prevalence is $2-3 \%$ of all gynecological emergencies and it is the fifth most common surgical emergency (4). OT progresses with impaired circulation of ovarian peduncle by circling around its own axis incompletely or completely. Similar to other vascular pathologies, reduced venous return, extension of the ovaries, interstitial haemorrhage and oedema occur in in OTs. Partial ovarian rupture, ischemia and necrosis with subsequent arterial flow deterioration are observed. Diagnosis and treatment may be delayed because clinical findings in this process are nonspecific findings such as sudden abdominal pain, nausea, vomiting, leucocytosis, and fever $(5,6)$. Various methods such as inflammatory markers, greyscale ultrasonography, Doppler ultrasonography and tomography are used 
to help in the diagnosis of OT. However, diagnosing accurately is often difficult due to nonspecific findings $(7,8)$. An increase in the number of white blood cells (WBC) is frequently used clinically as an indicator of inflammation, and some studies have also presented that there was an increase in the number of WBCs in cases of OT (9). Furthermore, many inflammation-based scoring systems such as thrombocyte-lymphocyte ratio, prognostic nutritional index and neutrophil-lymphocyte ratio (NLR) have been used to predict the prognosis of inflammatory diseases (10). The final diagnosis of torsion is made by direct observation of the rotated ovary or adnexa with laparoscopy or laparotomy. Diagnostic values of clinical findings and laboratory tests are limited. Therefore, partial or complete loss of function of ovarian tissue may be caused in case of any delayed or incorrect diagnosis (11). The aim of this study is to evaluate women developing OT after $\mathrm{COH}$ for IVF treatment.

\section{MATERIAL AND METHOD}

The study was approved by the Ethical Committee of Beykoz University (Date: 21/12/2020, Decision No: 2020/4). All procedures were carried out in accordance with the ethical rules and the principles of the Declaration of Helsinki.

This retrospective case-control study was carried out in an IVF clinic between January 2015- December 2020 . The medical records of 5186 IVF patients were examined and 1207 of these patients were PCOS. Ten cases who definitely diagnosed as OT were evaluated in this study. All OT patients were PCOS resistant to other treatments. None of the patients were pregnant because we prefer frozen-thawed embryo transfer in all PCOS patients to decrease ovarian hyperstimulation syndrome (OHSS) risk. Our OHSS prevalence is less than 1\% because of all freze strategy and analog trigger use. More than 20 oocytes were retrieved in 8 of 10 OT cases. None of the OT cases had ovarian cysts or OT history before $\mathrm{COH}$ treatment. We followed up the patients till the start of third menstrual cycleLaparoscopy was performed in all cases for treatment and we didn't perform ooferectomy in any cases and they were treated conservatively with ovarian detorsion. All patients were discharged at postoperative second day without any complication.

Data were analyzed according to demographic, clinicopathological, and sonographic findings. The patients were informed that previous patient files would be used during the research. They were free to be enrolled and leave the study at any time, and there would not be any research expense claimed to the family or social security institution, and individual information would be kept confidential.

\section{Stimulation Protocol}

In all PCOS patients, the $\mathrm{COH}$ were performed using the $\mathrm{GnRH}$ antagonist (Cetrotide, $0.25 \mathrm{mg}$, Merck Serono, İstanbul, Turkey) with a combination of rFSH (Gonal-F, Merck Serono, İstanbul, Turkey) and ovulation induction with GnRHa (0.2 mg, GonapeptylVR, Ferring Pharmaceuticals Ltd., Mumbai, India). Oocyte collection was performed 35-36 hours after the ovulation induction. The vitrification of blastocysts were performed using the Cryotop method, as described by the manufacturer (Kitazato, BioPharma Co. Ltd., Fuji, Japan).

\section{Statistical Analysis}

The statistical data analysis was conducted through SPSS (Statistical Package for the Social Sciences) 23.0 package program(SPSS Inc., Chicago, IL, USA). The categorical measurements were summarized as numbers and percentages. Continuous measurements, on the other hand, were summarized as mean and standard deviation (median and minimum-maximum when needed).

\section{RESULTS}

Ten of 5186 IVF patients had OT (10/5186; 0.19\%) and all OT cases were PCOS. The mean age of OT patients was $27.3 \pm 4.1$ years and the mean body mass index (BMI) was $23.5 \pm 6.2 \mathrm{~kg} / \mathrm{m}^{2}$ respectively. The mean number of retrieved oocytes was $21.46 \pm 4.12$. The average diameter of the twisted ovaries of patients was $121.4 \pm 56.1 \mathrm{~mm}$. Laparoscopy was performed in all OT patients for detorsion of the ovaries. It was found that OT occurred more frequently on the right side (8/10;80\%). Ovarian edema, abnormal adnexal positions, free fluid in the pouch, and absence/decreased blood flow in the ovary, occurred in $3,5,10$, and 4 cases, respectively. The period between oocyte pick-up(OPU) and OT changed between 2-10 days. Table shown complete blood count features of cases. It was determined as a result of analysis that mean Red distrubution width (RDW) value of the patients was $15.3 \pm 6.5 \%$ and platelet distribution width (PDW) values were determined as $15.9 \pm 2.7 \mathrm{fL}$ while mean platelet volume (MPV) values were $8.0 \pm 1.1 \mathrm{fL}$. It was also determined that the neutrophil levels of the patients were $10.9 \pm 3.2 \%$ and the lymphocyte levels were $1.4 \pm 0.7 \%$. The mean Neutrophile lymphocyte ratio (NLR) value of the patients who were included in the study was found to be $11 \pm 8.2$.

Table. Complete blood count features of cases

\begin{tabular}{|c|c|c|}
\hline & Mean $\pm S D$ & Mdn (Min-Max) \\
\hline $\mathrm{WBC}(\times 1000 / \mathrm{mL})$ & $13100.4 \pm 3270.1$ & $12500(7800-21000)$ \\
\hline RDW (\%) & $15.3 \pm 6.5$ & $13.9(12.1-39,2)$ \\
\hline PDW (fL) & $15.9 \pm 2.7$ & $16.6(6.2-17.2)$ \\
\hline Neutrophile (\%) & $10.9 \pm 3.2$ & $11.4(6.1-17.3)$ \\
\hline Lymphocyte (\%) & $1.4 \pm 0.7$ & $1.2(0.5-3.2)$ \\
\hline NLR & $11.0 \pm 8.2$ & $7.1(3.6-29.6)$ \\
\hline MPV (fL) & $8.0 \pm 1.1$ & $7.8(6.6-10.1)$ \\
\hline
\end{tabular}




\section{DISCUSSION}

We found increased risk of OT in PCOS patients undergoing IVF treatment. Ovarian stimulation is the predisposing factor for OT by increasing the ovarian weight and volume. OT should be suspected and excluded in any woman who has undergone $\mathrm{COH}$ for IVF and admits with a complaint of severe abdominal pain. Any delay in diagnosis and treatment may cause ovarian ischemic necrosis (12). Symptoms are nonspecific, and there may be severe and localized right or left lower abdominal pain and palpable bulk and peritoneal findings can be faced with. According to Shadinger et al. (13) all patients (100\%) had abdominal pain as the main symptom, while $85 \%$ of them had vomiting, $56 \%$ of them had leucocytosis, and $18 \%$ had a recorded fever. Also, in our patients the only consistent symptom was abdominal pain which is localized in the lower abdominal quadrant. Similar to Sahlu's (14) study the age of the OT patients was between 23-31 years. Laboratory tests which are requested at the diagnosis stage should include a complete blood count $(\mathrm{CBC})$ and a complete metabolic panel. If the torsion is causing bleeding and inflammation, $\mathrm{CBC}$ may indicate anemia or leucocytosis as a response. These laboratory abnormalities are not specific and the laboratory values will appear normal in torsion most of the time (15). In our cases there was no anemia but 7 (70\%) of the cases had leucocytosis. In a study, the increase in the leucocyte count of patients who were diagnosed with adnexal torsion was found to be 36.5-64\% (15). Eriç et al. (16) found in their study that the leucocyte count was found to be significantly higher in patients with ovarian torsion than the patients in the other groups. NLR is studied as a biomarker in cardiovascular diseases, malignancy, diabetes, hypertension, autoimmune diseases, gynaecology and obstetric diseases (17-20) Soysal et al. (21) conducted a study and presented that NLR can be used in the discrimination of preoperative ovarian cysts and torsion, but it has no diagnostic value in discriminating ovarian cyst rupture and torsion. It was found in a study by Eriç et al. (16) that the NLR values in the group with OT were found to be significantly higher than the other groups. Similarly to this study, we also found high NLR value (11.0 \pm 8.2$)$ in our study. Despite the studies emphasizing that the increase in MPV and RDW expansion in inflammatory cases such as acute appendicitis, there are also some other studies pointing that there is no relationship between adnexal torsion and MPV (21). A study which was carried out by Eriç et al. (16) revealed that there was no difference between groups according to RDW and MPV.In our study, the mean RDW was $15.3 \pm 6.5 \%$ while the mean MPV was found to be $8.0 \pm 1.1$. In agreement with previous results, we found that OT occurred more frequently on the right side $(8 / 10 ; 80 \%)(22,23)$.
Because right infundibulopelvic ligament is longer than the left one and the descending colon has a protective nature on the left side. The frequency of OT is increased in women undergoing ovulation induction with gonadotropins, especially in those with OHSS. Three studies determined the incidence of OT after IVF to be $0.08-0.13 \%$ (24-26). A few case reports of OT associated with PCOS have been reported, but the correlation between PCOS and OT is not strongly shown $(27,28)$. But in our study all of the 10 cases were PCOS. This might be due to the increased size of the ovary, and resulting hypermobility of ovaries during $\mathrm{COH}$. . Enlarged cystic ovaries because of ovarian stimulation, especially when complicated by OHSS, may predispose ovaries to torsion (29-31). When patients conceive after $\mathrm{COH}$ and in the setting of OHSS, the ovarian cysts persist and this increases the risk of an OT (26). Mashiach et al. (31) (1990), investigating 201 ovarian stimulation cycles complicated by OHSS, found $15(7.5 \%)$ patients to have the complication of unilateral OT. In contrast to this study,OT risk is very low in our patient group $(0.19 \%)$ because of widely used freeze-all strategy. Similarly,in a study conducted by Berkkanoğlu et al. (32) OT risk was low in freeze-all group.

We didn't perform oopherectomy in any cases and there was no embolisation after detorsion. The conservative surgical management of OT should be encouraged to ensure the preservation of ovarian function.In any suspicion for OT, diagnostic laparoscopy should be indicated to preserve ovarian function and future fertility.

Limitations of the study: The low number of patients and retrospective study design were among the limitations of our study.

\section{CONCLUSION}

It is concluded that OT is more common in the cases with PCOS. The risk of OT is reduced by decreasing gonadotropin dosage as well as retrieved number of oocyte. Also,prefering frozen-thawed embryo transfer can decrease OT risk in PCOS patients.

\section{ETHICAL DECLARATIONS}

Ethics Committee Approval: The study was approved by the Ethical Committee of Beykoz University (Date: 21/12/2020, Decision No: 2020/4).

Informed Consent: Because the study was designed retrospectively, no written informed consent form was obtained from patients.

Referee Evaluation Process: Externally peer-reviewed.

Conflict of Interest Statement: The authors have no conflicts of interest to declare. 
Financial Disclosure: The authors declared that this study had received no financial support.

Author Contributions: All of the authors declare that they have all participated in the design, execution, and analysis of the paper and that they have approved the final version.

\section{REFERENCES}

1. Speroff L, Fritz MA. Clinical gynecologic endocrinology and infertility: 7th ed.Philedelphia.Lippincott Williams \& Wilkins, 2005.

2. Raouf N, Hikmat R, Munib A, Shamdeen M, Salahaldeen R, Abdullah H. Success of controlled ovarian hyperstimulation and intrauterine insemination in couple with unexplained infertility. J Womens Health Dev 2020; 3: 77-9.

3. Firouz M, Noori N, Ghasemi M, Dashipour A, Keikha N Comparing the effectiveness of doing intra-uterine insemination 36 and 42 hours after human chorionic gonadotropin (HCG) injection on pregnancy rate: a randomized clinical trial. J Family Reprod Health 2020; 14: 173-9.

4. Hibbard LT. Adnexal torsion. Am J Obstet Gynecol 1985; 152: 456-61.

5. Bekci T, Polat AV, Aslan K, Tomak L, Bilgici MC, Danaci M. Diagnostic performance of diffusion-weighted MRI in the diagnosis of ovarian torsion: comparison of torsed and nonaffected ovaries. Clin imaging 2016; 40: 1029-33.

6. Albayram F, Hamper UM. Ovarian and adnexal torsion: spectrum of sonographic findings with pathologic correlation. J Ultrasound Med 2001; 20: 1083-9.

7. Wilkinson C, Sanderson A. Adnexal torsion-a multimodality imaging review. Clin Radiol 2012; 67: 476-83.

8. Chang HC, Bhatt S, Dogra VS.Pearls and pitfalls in diagnosis of ovarian torsion. Radiographics 2008; 28: 1355-68.

9. Sasaki KJ, Miller CE. Adnexal torsion: review of the literature. J Minim Invasive Gynecol 2014; 21: 196-202.

10. Tanrikulu Y, Tanrikulu CS, Sabuncuoglu MZ, Kokturk F, Temi $\mathrm{V}$, Bicakci E. Is the neutrophil-to-lymphocyte ratio a potential diagnostic marker for peptic ulcer perforation? A retrospective cohort study. Am J Emerg Med 2016; 34: 403-6.

11. Cass DL. Ovarian torsion. Semin Pediatr Surg 2005; 14: 86-92.

12. Krishnan S, Kaur H, Bali J, Rao K. Ovarian torsion in infertility management-Missing the diagnosis means losing the ovary: ahigh price to pay. J Hum Reprod Sci 2011; 4: 39-42.

13. Shadinger L, Andreotti RF, Kurian RL. Preoperative sonographic and clinical characteristics as predictors of ovarian torsion. J Ultrasound Med 2008; 27: 7-13.

14. Sahlu Z, Negash S, Yusuf L. Adnexal torsion a five-years retrospective review in two hospitals. Ethiop Med J 2014; 52: 15564

15. Mazouni C, Bretelle F, Menard J, Blanc B, Gamerre M. Diagnosis of adnexal torsion and predictive factors of adnexal necrosis. Gynecol Obstet Fertil 2005; 33: 102-6.

16. Eric J, Balcı O. Diagnostic value of neutrophil to lymphocyte ratio in over torsion. Bozok Tip Der 2018; 8: 127-33.

17. Bhat T, Teli S, Rijal J, et al. Neutrophil to lymphocyte ratio and cardiovascular diseases: Review. Expert Rev Cardiovasc Ther 2013; 11: 55-9.

18. Tanrikulu CS, Tanrikulu Y, Sabuncuoglu MZ, Karamercan MA, Akkapulu N, Coskun F. Mean platelet volume and red cell distribution width as a diagnostic marker in acute appendicitis. Iran Red Crescent Med J 2014; 16: 10211.
19. Yilmaz H, Celik H, Namuslu M, et al. Benefits of the neutrophilto-lymphocyte ratio for the prediction of gestational diabetes mellitus in pregnant women. Exp Clin Endocrinol Diabetes 2014; 122: 39-43.

20.Guzel AI, Kokanali MK, Erkilinc S, et al. Predictive role of the neutrophil lymphocyte ratio for invasion with gestational trophoblastic disease. Asian Pac J Cancer Prev 2014; 15: 4203-6.

21.Soysal S, Baki RB. Diagnostic value of neutrophil to lymphocyte ratio in differentiation of ruptured ovarian cysts and adnexal torsion. Turk J Obstet Gynecol 2018; 15: 91-4.

22. Hyttel TE, Bak GS, Larsen SB, Lokkegaard EC: Re-torsion of the ovaries. Acta Obstet Gynecol Scand 2015; 94: 236-44.

23. Weitzman VN, DiLuigi AJ, Maier DB, Nulsen JC. Prevention of recurrent adnexal torsion. Fertil Steril 2008; 90: 2018.

24. Roest J, Mous HV, Zeilmaker GH, Verhoeff A. The incidence of major clinical complications in a Dutch transport IVF programme. Hum Reprod Update 1996; 2: 345-53.

25. Govaerts I, Devreker F, Delbaere A, Revelard P, Englert Y. Shortterm medical complications of 1500 oocyte retrievals for in vitro fertilization and embryo transfer. Eur J Obstet Gynecol Reprod Biol 1998; 77: 239-43.

26. Gorkemli H, Camus M, Clasen K.Adnexal torsion after gonadotrophin ovulation induction for IVF or ICSI and its conservative treatment. Arch Gynecol Obstet 2002; 267: 4-6.

27. Tay J, Parker H, Dhange P, Paton-Forrester C, Atiomo W. Isolated torsion of the fallopian tube in a patient with polycystic ovarian syndrome (PCOS). Eur J Obstet Gynecol Reprod Biol 2010; 150: 218-9.

28. Matsuoka S, Kobayashi T, Kusunoki S, Ogishima D. Polycystic ovary syndrome with asynchronous bilateral adnexal torsion in a natural cycle. BMJ Case Rep 2017: bcr-2016218880.

29. Ben-Rafael Z, Bider D, Mashiach S. Laparoscopic unwinding of twisted ischemic hemorrhagic adnexa after in vitro fertilization. Fertil Steril 1990; 53: 569-71.

30.Kemmann E, Ghazi DM, Corsan GH. Adnexal torsion in menotropin-induced pregnancies. Obstet Gynecol 1990; 76: 4036

31. Mashiach S, Bider D, Moran O, Goldenberg M, Ben-Rafael Z. Adnexal torsion of hyperstimulated ovaries in pregnancies after gonadotropin therapy. Fertil Steril 1990; 53: 76-80.

32. Berkkanoglu M, Coetzee K, Bulut H, Ozgur K. Risk of ovarian torsion is reduced in GnRH agonist triggered freeze-all cycles: a retrospective cohort study. J Obstet Gynaecol 2019; 39: 212-17. 